\title{
Prevalence of chlamydial infection in promiscuous
}

\section{women}

\author{
P E MUNDAY, G PRITCHARD, J R W HARRIS, AND D TAYLOR-ROBINSON \\ From the Sexually Transmitted Diseases Research Group, MRC Clinical Research Centre, Harrow, \\ Middlesex; and the Praed Street Clinic, St Mary's Hospital, London
}

SUMMARY Chlamydia trachomatis was isolated from the cervix of $18(33 \%)$ of 55 women who admitted to two or more casual sexual contacts in contrast to one (3\%) of 32 women who admitted to one casual contact in the preceding month. The chlamydial infections did not produce characteristic clinical features. Since promiscuous women are at high risk of acquiring chlamydial infection, they should be regarded as a priority group when resources for chlamydial isolation are limited.

\section{Introduction}

There is convincing evidence that Chlamydia trachomatis is a pathogen in both the male and female genital tracts. ${ }^{1}$ It is also clear that chlamydial infections are not associated with distinctive symptoms or signs which would enable a clinician to make an accurate diagnosis without recourse to laboratory help..$^{2-5}$ Access to a diagnostic chlamydial isolation service is not widely available, however, since the techniques are labour intensive and expensive. In the absence of such a service most clinicians now treat women who are contacts of men with non-gonococcal urethritis (NGU) with antibiotics active against chlamydiae, since it has been shown that about one third of such women harbour chlamydiae in the cervix. ${ }^{3-8}$ Furthermore, a similar proportion of women who have gonorrhoea or who are contacts of men with gonorrhoea are chlamydia-positive, and it has been proposed ${ }^{910}$ that treatment regimens for the management of patients with proved or suspected gonorrhoea should incorporate antichlamydial agents.

Most workers ${ }^{2}{ }^{7}$ have shown that women who do not have a history of contact with a man who has urethritis have a low prevalence of chlamydial infection. Some women attending sexually transmitted diseases (STD) clinics, however, do not have a regular consort to inform them of the development of urethritis. These women include

Address for reprints: Dr P E Munday, Praed Street Clinic, St Mary's Hospital, London W2

Accepted for publication 24 October 1982 prostitutes attending regularly for routine examination and women who are seeking reassurance after a casual encounter outside their stable relationship. Since the prevalence of chlamydial infection in such groups is unknown, we have undertaken a study in which women presenting for examination who admitted contact with untraceable male partner(s) were investigated.

\section{PATIENTS AND METHODS}

Women attending an STD clinic were included in the study if they had had sexual intercourse in the preceding 28 days with one or more men whom they could not identify and providing they had not subsequently had intercourse with a known partner. Women who had taken antibiotics in the preceding 28 days were excluded as were those who were known to be contacts of men with gonorrhoea or NGU. Consent to undertake this study was given by the ethics committee.

A routine clinical examination was performed and a specimen taken from the cervix with a polyester sponge $\mathrm{swab}^{11}$ for isolation of chlamydiae. The swab was expressed in sucrose-phosphate medium (2SP) containing $10 \%$ fetal calf serum and the medium was then snap-frozen in liquid nitrogen for transport to the laboratory. The specimens were tested for $C$ trachomatis in cycloheximide-treated McCoy cell cultures as described. ${ }^{12}$

\section{Results}

Eighty-seven women were studied and chlamydiae were isolated from $19(22 \%)$ of them. Nine of 29 
$(31 \%)$ prostitutes were chlamydia-positive in contrast to 10 of $58(17 \%)$ other women admitting one or more casual contacts. The chlamydial isolation rates in relation to the number of admitted contacts are shown in the table. Chlamydiae were isolated from 18 of $55(33 \%)$ women who had two or more contacts compared with one of $32(3 \%)$ women who had only one contact.

Fifty-eight women had symptoms and $12(21 \%)$ were chlamydia-positive as were seven of the 29 $(24 \%)$ asymptomatic women. Fifty-three women had abnormal physical signs and $13(25 \%)$ were chlamydia-positive as were six of the $34(18 \%)$ women in whom physical examination was normal.

TABLE Isolation of Chlamydia trachomatis from the cervix of women in relation to number of admitted sexual contacts in the preceding month

\begin{tabular}{lll}
\hline & \multicolumn{2}{c}{ Patients from whom chlamydiae were isolated } \\
\cline { 2 - 3 } No of contacts & No (\%) positive & No tested \\
\hline 1 & $1(3)$ & 32 \\
$2-9$ & $11(32)$ & 34 \\
$\geqslant 10$ & $7(33)$ & 21 \\
Total & $19(22)$ & 87 \\
\hline
\end{tabular}

\section{Discussion}

The results of this study indicate that promiscuous women, regarded here as those who have sexual intercourse with unknown male partners, are at considerable risk of harbouring chlamydiae. Furthermore, in agreement with the findings of other workers $^{2-5} 7$ the presence of symptoms or abnormal physical signs does not distinguish between women who are or who are not infected with chlamydiae. The risk of infection with chlamydiae is minimal for those women admitting only one casual contact and is similar to that of other women attending an STD clinic without a history of contact with NGU or gonorrhoea. The risk increases dramatically, however, when two or more contacts are admitted and is similar to that of women who are known contacts of men with urethritis. Since it is considered reasonable to treat such contacts on epidemiological grounds, both to prevent reinfection of their partner and to prevent serious sequelae-for example, salpingitis, it might be argued that sexual contact with more than one unidentified man is an indication for antichlamydial treatment. This would lead to a situation in which prostitutes attending a clinic weekly for examination could find themselves taking antibiotics indefinitely. Since this would be expensive and unacceptable to the patient and the microbiologist a chlamydial isolation service would seem to be essential to determine which of these high risk patients needs treatment. When resources are limited, priority should be given to specimens obtained from these women.

\section{References}

1. Taylor-Robinson D, Thomas BJ. The role of Chlamydia trachomatis in genital-tract and associated diseases. $J$ Clin Pathol 1980; 33:205-33.

2. MacD Burns DC, Darougar S, Thin RN, Lothian L, Nicol CS. Isolation of Chlamydia from women attending a clinic for sexually transmitted disease. $B r J$ Vener $D i s$ 1975; 51:3148.

3. Nayyar KC, O'Neill JJ, Hambling MH, Waugh MA. Isolation $\omega$ of Chlamydia trachomatis from women attending a clinic for sexually transmitted diseases. Br J Vener Dis 1976; 52:396-8.

4. Woolfitt JMG, Watt L. Chlamydial infection of the urogenital tract in promiscuous and non-promiscuous women. $\mathrm{Br} J$ Vener Dis 1977; 53:93-5.

5. Willcox RR. Epidemiological importance of concealed nongonococcal urethritis. Br J Vener Dis 1979; 55:149-53.

6. Hilton AL, Richmond SJ, Milne JD, Hindley F, Clarke SKR. Chlamydia $\mathrm{A}$ in the female genital tract. $\mathrm{Br} J$ Vener Dis 1974; 50: $1-10$

7. Oriel JD, Powis PA, Reeve P, Miller A, Nicol CS. Chlamydial infections of the cervix. Br J Vener Dis 1974; 50:11-6.

8. Tait IA, Rees E, Hobson D, Byng RE, Tweedie MCK. Chlamydial infection of the cervix in contacts of men with nongonococcal urethritis. Br J Vener Dis 1980; 56: 37-45.

9. Willcox JR, Fisk PG, Barrow J, Barlow D. The need for a chlamydial culture service. Br J Vener Dis 1979;55:281-3.

10. Taylor-Robinson D, Munday PE. Chlamydia culture service. Br J Vener Dis 1980; 56: 183.

11. Oates JK, Selwyn S, Breach MR. Polyester sponge swabs to facilitate examination for genital infection in women. $B r J$ Vener Dis 1971;47:289-92.

12. Munday PE, Johnson AP, Thomas BJ, Taylor-Robinson D. A comparison of the sensitivity of immunofluorescence and Giemsa for staining Chlamydia trachomatis inclusions in cycloheximide treated McCoy cells. J Clin Pathol 1980; 三 33:177-9. 